\title{
Cosmopolitismo y las barreras insalvables de la cultura y los gustos en La ética protestante y el espíritu del capitalismo de Max Weber ${ }^{*}$
}

\author{
LUIS FERNANDO BUSTAMANTE ZaPATA**
}

Artículo recibido: 8 de agosto 2014

Artículo aprobado: 30 de octubre de 2014

Doi: dx.doi.org/10.12804/desafios27.01.2015.01

Para citar este artículo: Bustamante, Z. L. F. (2015). Cosmopolitismo y las barreras insalvables de la cultura y los gustos en La ética protestante y el espíritu del capitalismo de Max Weber. Desafios 27(1), 15-45. doi: dx.doi.org/10.12804/desafios27.01.2015.01

\section{Resumen}

Una revisión de La ética protestante y el espíritu del capitalismo de Max Weber revela que la palabra cultura es explicitamente mencionada al menos 43 veces en la obra, dependiendo de la traducción y la edición. La cultura toma relevancia debido a que ocupa un lugar de partida para la estructura argumentativa del texto, pues de esta forma se diferencian los grupos humanos y sus peculiares características. Ante una mirada cosmopolita, la inquietud de Weber sobre la cultura en este texto es de gran inspiración, dadas las variadas corrientes de pensamiento global, su disemina-

\footnotetext{
* Este artículo de reflexión derivado de investigación es producto del trabajo de grado del autor para optar por título de Doctor en Humanidades de la Universidad EAFIT.

** Negociador Internacional, Magíster en Administración y candidato a Doctor en Humanidades de la Universidad EAFIT. Actualmente se desempeña como Gerente en Comercializadora y Representaciones Antiotrading S.A.S. Correo electrónico: lfbustamantez@gmail.com
} 
ción reciente y la aceptación entre los círculos académicos. Con el cosmopolitismo como guia principal, este texto analiza el uso de la palabra cultura en la obra y propone un debate para la construcción de un ethos cosmopolita. Aunque persiste la inquietud sobre los mecanismos ético-politicos aplicables, la literatura cosmopolita se acerca a la educación como respuesta a los problemas de la cultura en un mundo globalizado. Palabras clave: Cosmopolitismo, cultura, Max Weber, educación.

\title{
Cosmopolitism and the Unbreakable Barriers of Culture and Tastes in Max Weber's Protestant Ethic and the Spirit of Capitalism
}

\begin{abstract}
An analysis of Max Weber's The Protestant Ethic and the Spirit of Capitalism reveals that the word "culture" is explicitly mentioned at least 43 times depending on the edition and translation. Culture is relevant as the foundation of the argumentative structure since it allows for the differentiation of human groups and theirpeculiar characteristics. From a cosmopolitan point of view, Weber's question is still pertinent given the advances of global thinking, its recent dissemination, and its acceptance within academic circles. With cosmopolitanism as its main guide, this paper analyses the use of the word "culture": in order to inspire a debate on how to define a cosmopolitan ethos. While there is a persistent inquiry onto the applicable ethical-political mechanisms, the cosmopolitan literature converges towards education as an answer to the problem of culture in a globalized world.
\end{abstract}

Keywords: Cosmopolitism, culture, Max Weber, education.

\section{Cosmopolitismo e as barreiras insuperáveis da cultura e os gostos $\mathrm{Na}$ ética protestante e o espírito do capitalismo de Max Weber}

\begin{abstract}
Resumo
Uma revisão de A Ética Protestante y el Espíritu del Capitalismo de Max Weber revela que a palavra cultura é explicitamente mencionada pelo menos 43 vezes na obra dependendo da tradução e edição. A cultura toma relevância, devido
\end{abstract}


a que ocupa um lugar de partida para a estrutura argumentativa do texto pois desta forma se diferenciam os grupos humanos e suas peculiares características. Ante uma olhada cosmopolita, a inquietude de Weber sobre a cultura neste contexto é de grande inspiração dada as variáveis correntes de pensamento global, sua disseminação recente e a aceitação entre os círculos académicos. Com o cosmopolitismo como guia principal, este texto analisa o uso da palavra cultura na obra para propor um debate para a construção de um ethos cosmopolita. Ainda que persiste a inquietude sobre os mecanismos ético-políticos aplicáveis, a literatura cosmopolita se aproxima à educação como resposta aos problemas da cultura em um mundo globalizado.

Palavras-chave: Cosmopolitismo, cultura, Max Weber, educação.

\section{Introducción}

Los interrogantes producto del fenómeno que se denomina cultura son la razón por la cual la obra de Max Weber (2003) titulada La ética protestante y el espiritu del capitalismo, entre sus párrafos iniciales, reza:

Tratar de los problemas de la historia universal para un hijo del moderno mundo cultural europeo, implica necesaria y legítimamente plantearlos desde la siguiente problemática: ¿qué serie de circunstancias han llevado precisamente en el suelo de Occidente, y solo aquí, se hayan dado ciertas manifestaciones culturales, mismas que -al menos tal y como solemos representárnoslasse encuentran en una dirección evolutiva de alcance y validez universales? (p. 53).

La separación de diferentes grupos humanos (mundo cultural europeo y los demás), como objeto de observación que Weber aprecia con el propósito de sustentar su argumento central, implica también alguna trascendencia del concepto o noción de cultura. Si el carácter ontológico de la pregunta planteada por el autor no es ya un reto para el entendimiento, las repercusiones de su obra, las múltiples interpretaciones, la variedad de aplicaciones y la actualidad de su pensamiento ciertamente lo son para la academia contemporánea. 
Las obras de Weber, con las normales limitaciones de todo ejercicio crítico o de investigación, inspiraron trabajos por fuera de las manifestaciones culturales dadas en las circunstancias de occidente, ${ }^{1}$ que posibilitan asumir que tienen cierto contenido o aplicabilidad en un ámbito cosmopolita, más allá del alcance teórico y metodológico de cualquier obra, por medio de la cual los científicos amplían el espectro del conocimiento y más allá del etnocentrismo visible en la universalización de occidente. Reseñar cada publicación de Weber que pueda inspirar debates en el cosmopolita es una labor titánica, pero con el ánimo de ilustrar la lectura, algunos trabajos serán expuestos.

Para empezar, un artículo sobre la expansión del sistema capitalista en Japón afirma que, mucho antes de Weber, existían en este país los valores y condiciones necesarias para el desarrollo del capitalismo y, que a pesar de su esfuerzo, él no logró diferenciarlos (Jacobs, 2010). Desde esta perspectiva, aunque Weber asociara estos valores y condiciones al protestantismo, diferentes grupos humanos también cultivaban los elementos necesarios para valerse de un capitalismo. ${ }^{2}$ Con el ánimo de no prolongar o dar vida a ningún misterio, es necesario aclarar que algunos de los valores y condiciones aptos para el desarrollo del capitalismo que Weber (2003) observó en los grupos humanos occidentales son trabajo duro, economía racional de generación de riqueza y habilidades empresariales.

Otro particular interés de Weber residía en la comparación sociológica de las religiones, pues ellas, concluyó, impulsan al hombre a lograr sus

\footnotetext{
1 Aunque la expresión manifestaciones culturales, dadas en las circunstancias de occidente, es algo larga y poco cómoda, se trata de apegarse literalmente a las palabras con las cuales Weber denomina esta situación.

2 Weber (1968) partía de sus apreciaciones de la cultura China, suponiendo en esencia que todos los grupos humanos con influencia del confucianismo eran similares, lo cual consignó en su libro The religion of China: Confucianism and Taoism. Aunque él estaba consciente de que no tuvo acceso a fuentes primarias y que aquellas personas que consultó ofrecían un sesgo adicional a su trabajo, es de notar el esfuerzo por extender su método hasta oriente. Hoy en día es criticado, pero vale la pena reflexionar e imaginar las condiciones en las cuales elaboró esta obra.
} 
metas. Al respecto, fueron varias las publicaciones, destacándose su obra Sociología de la religión (2012) en la cual consigna sus reflexiones en torno al judaísmo, cristianismo, hinduismo y budismo. Partiendo de este texto, se encuentran trabajos que, para referencia, hacen un análisis histórico de las formas proféticas racionales que rompían con la tradición en el judaísmo para la instauración del capitalismo, gracias a sus movimientos de masas (Villacañas, 2009), y otros documentos que se enfocan en el islam critican el esencialismo cultural de Weber y lo actualizan a la luz de los estudios culturales contemporáneos (Matin-Asgari, 2004).

Presentados algunos antecedentes, el artículo aquí presente es producto de una lectura desde el cosmopolitismo de la La ética protestante y el espiritu del capitalismo de Max Weber, que conlleva la siguiente pregunta: ¿qué posible inspiración encuentra el cosmopolitismo en la obra específica de Weber para la construcción de un ethos cosmopolita? Para abrir la discusión, se parte de las barreras de la cultura y los gustos como punto de encuentro entre ambos, por medio del análisis del término cultura en La ética protestante y el espiritu del capitalismo. A continuación, se procede a diferenciar los tipos de cosmopolitismo para ilustrar dónde las barreras de la cultura y los gustos conectan ambas corrientes de pensamiento. Luego, se discuten las posibilidades para futuras investigaciones, con base en diferentes propuestas sobre educación en cosmopolitismo. Esta obra de Weber se presenta como guía para dar forma al espíritu cosmopolita y, a manera de herramienta metodológica, con el propósito de soportar el uso de la educación como herramienta política y moral de transición hacia una cosmópolis.

\section{Cosmopolitismo: definición y tipos}

Para comprender por qué el cosmopolitismo encuentra inspiración en la obra de Weber conviene entonces definirlo y tipificarlo. La idea de cosmopolitismo ciertamente se ha transformado desde el primer uso del término cosmopolita que Diógenes de Sinope, el cínico, hizo en la antigua Grecia. Así como él, parece sensato que para auto-denominarse ciudadano del mundo haya que desahuciarse y surcar al garete un 
mundo sin fronteras, ${ }^{3}$ sin apegos, sin nacionalidades, sin necesidades materiales (Desmond, 2008). No se es ciudadano de ningún lugar, ni tampoco se es ajeno. Al respecto, un ejercicio de investigación en Alemania confirma que la clave del pensamiento cosmopolita en los grupos humanos tiene su base en el relacionamiento trasnacional (Mau, Mewes \& Zimmermann, 2008). De la misma manera, es posible afirmar que una emancipación cosmopolita resulta dejar de lado la idea de una cultura occidental universal (Pieterse, 2006). Dado lo anterior en la globalización, como conducto de las relaciones humanas sin barreras físicas gracias al avance de las tecnologías de la información y la comunicación y del comercio internacional.

Después de Diógenes el Cínico, surgirán ideas cosmopolitas no necesariamente plurales en los pensadores cristianos, representadas en personajes como Erasmo de Rotterdam (1466-1536) con su ideal de paz mundial (Egan, 2004) y en Francisco de Vitoria (1483-1546) con su noción de república del mundo entero (res publica totius orbis), y a quien se considera uno de los padres fundadores del derecho internacional (Shelton, 2013). No obstante los avances cristianos, dos centurias fueron necesarias para que el cosmopolitismo fuera retomado en la modernidad. Es posible que los primeros proyectos modernos de cosmopolitismo estén inspirados por la obra de Immanuel Kant (1784) titulada Idea para una historia universal en sentido cosmopolita donde introduce la idea de que todos los seres humanos pertenecen a una sola comunidad moral.

La importancia y la lista de trabajos sobre cosmopolitismo es mucho más amplia y desarrollada de lo que pensó Scheffler (1999) a finales del siglo Xx, o lo que el amplio trabajo de Hansen (2010) una década después logró complementar. Este último logró recopilar más de sesenta documentos de primera importancia en el tema, publicados

\footnotetext{
3 Si bien los documentos históricos son algo ambiguos en ubicar a Diógenes de Sinope y diferenciar los hechos históricos de las leyendas, sus enseñanzas quizás se refieren más al desarme cultural y político, y a aceptar la pobreza en el entendimiento para asumir los retos de la inclusión, las relaciones humanas y la convivencia. Desde esta perspectiva, más que un apátrida o antisocial, todo un maestro fue entonces el cínico.
} 
durante la última década del siglo Xx y la primera del siglo XXI, que abordan qué es cosmopolitismo.

Una revisión documental sobre el tema revela que existen al menos cinco tipos de cosmopolitismo a considerar: político, moral (estricto y moderado), económico, recientemente se habla de cosmopolitismo cultural (Kleingeld \& Brown, 2002) y, en adición a estos, social (Janssens \& Steyaert, 2012). Adicionalmente, también es posible agrupar dos corrientes de cosmopolitismo: uno emancipatorio, consignado en las propuestas de Vitoria, Kant, y Marx; y otro gerencial en el cristianismo medieval, el imperialismo y el globalismo (Mignolo, 2000). De esta forma, se configuran varias facetas de cosmopolitismo.

El cosmopolitismo político, la corriente más antigua y probablemente más prolífica, proviene de los estoicos en la Antigua Grecia, bebe de la obra de Kant (1784) y está representado en autores como Martha Nussbaum (1994, 1997) y David Held (1995, 2002, 2010), entre otros. De alguna manera, el cosmopolitismo político es afín al pluralismo y su objetivo principal es definir la estructura política de un gobierno supranacional, la concepción de una justicia global, el establecimiento de unos derechos humanos y la descripción del papel del ciudadano del mundo. Feldman (2007), en la corriente asociada con el derecho, afirma que "el cosmopolitismo generalmente desvía nuestra atención de las asociaciones políticas como los estados a manera de constructores de categorías morales relevantes. $\mathrm{Al}$ tratar al individuo como primario, y a sus asociaciones políticas como secundarias, el cosmopolitismo puede aclarar el camino para vislumbrar deberes morales, éticos y también, legales" (p. 1025). Es así como se llega a un cosmopolitismo moral, ya que ningún mecanismo de representación en la democracia permitirá centrarse principalmente en el individuo por encima de otros entes de la sociedad, puesto que desemboca en la típica sociedad de masas que Weber tanto escudriñó (Villacañas, 2005).

\footnotetext{
4 Traducción por el autor, el texto original dice: "cosmopolitanism generally directs our attention away from political associations like states as relevant makers of moral categories. By treating the individual as primary, and his or herpolitical associations as secondary, cosmopolitanism can clear the way to imagining not only moral and ethical but also legal duties".
} 
El cosmopolitismo moral se encuentra fuertemente atado al desarrollo del cosmopolitismo político. Por ende, resulta interesante observar cómo el discurso ético del cosmopolitismo danza entre el problema del universalismo sin guía (McCarthy, 2011) y el imperialismo global (Dallmayr, 2005) como posibles desembocaduras indeseables de este movimiento. En consecuencia, las raíces del cosmopolitismo no deben tener base en un ciudadano cuya personalidad sea "un amante de la humanidad en abstracto, o un coleccionista de culturas y religiones como especímenes de museo para catalogar, preservar y analizar" (Reno, 2008, p. 135), ya que tal corriente conservadora, racional, se priva de establecer empatías y relaciones humanas por fuera de un racionalismo asfixiante. De allí, se desprende el cosmopolitismo cultural, que busca un cambio en los medios de relacionamiento de los hombres, muy al estilo de la hermenéutica diatópica, al buscar recoger las voces de los diferentes grupos humanos (Aguiló, 2010).

Este cosmopolitismo cultural es representado en autores como Appiah (2007) y Hannerz (1990), quienes se enfocan en los problemas del diálogo intercultural en un mundo cada día más conectado por la globalización. De esta manera, las investigaciones enfocadas en cosmopolitismo cultural son típicamente estudios de caso que buscan observar la transformación de los seres humanos que acumulan experiencias de vida en el exterior, es decir, que se conectan en el mundo con otros seres humanos por diversas vías. Por ejemplo, Colic-Peisker (2010) afirma que los individuos con mayor nivel educativo, que pueden ejercer su profesión en cualquier parte del mundo y que, por ende, han vivido en dos o más países, logran conformar una estructura de pensamiento, que si bien se basa en ideas universalistas como el concepto de humanidad, se acerca al pensamiento cosmopolita. Estos individuos no son apátridas ni anti-nacionalistas, por el contrario, manifiestan alto apego a sus raíces nacionales, pero además, un alto apego a su especialidad laboral y al grupo humano correspondiente (artistas, obreros, ingenieros, químicos, filósofos u

\footnotetext{
5 Traducción por el autor, el texto original dice: "lover of bumanity in abstract, nor does be collect cultures or religions as museum specimens to be catalogued, preserved, and analysed".
} 
otras profesiones). Han logrado vivenciar la teoría multinivel de la cultura para asociarse con los grupos humanos que en cada situación sean correspondientes de acuerdo con el mundo globalizado (Leung, Bhagat, Buchan, Erez \& Gibson, 2005).

Si bien la globalización es un factor importante en el cosmopolitismo cultural, su énfasis en la cultura da pie a diferenciar un cosmopolitismo social que reposa esencialmente en los movimientos mundiales de globalización, la interdependencia de los seres humanos y su ethos derivado. Este cosmopolitismo se encuentra en autores como Beck (2002, 2004), Beck y Sznaider (2006), ampliamente reconocidos por su trabajo sobre la globalización, y Delanty (2006, 2009, 2011, 2012), quien se preocupa por el impacto del cosmopolitismo en la teoría crítica y cambio social. De forma similar a Weber, esta escuela dirige su mirada sociológica a los fenómenos que interfieren o potencian la transformación de las sociedades, entre ellos, las barreras insalvables de la cultura y los gustos (una de las inspiraciones de este artículo).

Weber se preocupa por las barreras insalvables de los gustos y la cultura. El cosmopolitismo se preocupa por la interacción de las formas de vida de los diferentes grupos humanos, mediadas por una entidad superior, política y socialmente formada. Ambos dependen de una fundación ética compartida, trasmisible y de formación espontánea. Schroeder (1992), inspirado en esta idea, tipifica la obra de Weber dentro de la Sociología de la Cultura. El renovado interés sobre el estudio de la cultura en la obra general de Weber es relativamente reciente y se mantuvo inexplorado hasta finales del siglo Xx (Martindale, 1971). De acuerdo con Zeuner (2003), dicho interés está atravesado también por el debate sobre la presencia o ausencia del estudio de dicho fenómeno en su obra y sobre qué entendía Weber por cultura, lo que es aún más complicado.

El término cultura es uno de los conceptos cuya definición ha sido más debatida, en especial desde la antropología (Baldwin, Faulkner, Hecht \& Lindsey, 2006). Actualmente, se han popularizado las definiciones que asemejan la cultura a un conjunto de significados 
transmitidos por medio de símbolos (Geertz, 1995). En la definición de cultura existen puntos de encuentro: la cultura es un producto humano alterno a la naturaleza, transmitida de generación en generación que prepara para la vida con otros seres humanos (Ballesteros, 1962; Martínez, 1997). Por su parte, Weber se aproximó más al concepto de cultura desde sus textos metodológicos, que desde sus otras obras. En ellos, Weber (1949) se acercó al término afirmando que "“Cultura' es un segmento finito de la infinidad de sinsentidos de los procesos del mundo, un segmento sobre el cual los seres humanos confieren sentido y significancia" (p. 81). ${ }^{6}$

\section{Barreras insalvables del cosmopolitismo: la cultura en la ética protestante}

La cultura, entendida como se definió anteriormente, es un importante ingrediente en La ética protestante y el espiritu del capitalismo. ${ }^{7}$ Como palabra, es posible observar su uso cerca de 43 veces en el libro, incluyendo comentarios al pie de página y dependiendo de la edición. Con el propósito de observar cómo el término cultura se usó en el texto y a la vez permite inspirar conversaciones con el cosmopolitismo, se presenta el análisis de una de las ediciones del libro. Para soportar dicha conexión, se aplicó conteo y análisis de contenido (Bernard \& Ryan, 2010) del término cultura a partir de la edición del texto de Max Weber de 1991, La ética protestante y el espiritu del capitalismo de la editorial Premià, editado en México.

No obstante, resulta importante anotar que la obra completa de Weber no constituye un bloque monolítico, y es más bien el producto de diferentes ensayos publicados durante la vida del autor y con posterioridad a su muerte. Por ejemplo, La ética protestante y el espiritu

\footnotetext{
6 Traducción por el autor, el texto original dice: “'Culture' is a finite segment of the meaningless infinity of the world process, a segment on which human beings confer meaning and significance"

7 El primer registro de la tabla de análisis cita la expresión "ciertos sorprendentes hechos culturales" (Weber, 2003, p. 1). Sin duda, Weber bajo la observación científica tuvo éxito en diferenciar aspectos en la cultura que le permitirían argumentar su idea de un espíritu capitalista.
} 
del capitalismo es el resultado de dos artículos publicados en 1904 y 1905, después revisados y reeditados en 1920, que ubica la obra en un contexto histórico entre guerras. Con motivo de su centenario, se renovó el interés en el texto (Rodríguez, 2005) y se reafirmó su vigencia (Goldwaser, 2009), llegando incluso a extremos de buscar comprobar la tesis principal del libro en datos históricos, por medio de métodos cuantitativos (Sanderson, Abrutyn \& Proctor, 2011).

Para evitar maltratos e interpretaciones acomodadas de La ética protestante y el espíritu del capitalismo, es necesario resaltar que "lo que está en debate es un fenómeno cultural que, a largo plazo, también tiene repercusiones sobre las estructuras económicas, un nuevo ethos, que representa una ruptura de la visión tradicional del trabajo y la actividad económica"8 (Riesebrodt, 2012, p. 159). ${ }^{9}$ En palabras de Hennis (1983), "el tema de La ética protestante y el espíritu del capitalismo, tanto en 1905 como en 1920, era descubrir, mediante una exposición histórica, el origen de la moderna «racionalización de la conducta»" (p. 58).

Con lo anterior en mente, el análisis de contenido aplicado indaga cada uso explícito de la palabra 'cultura', resumido en veintisiete registros comentados, y de ser necesario, agrega una advertencia de irrelevancia de acuerdo con la definición presentada de cultura y cosmopolitismo. El mencionado análisis es la base para luego explicar por qué el cosmopolitismo encuentra inspiración en esta obra de Weber. En principio, conviene observar en la tabla 1 cómo Weber profundiza en el estudio de un grupo humano para fundamentar su tesis de una ética protestante. De la misma manera, el estudioso del cosmopolitismo deberá profundizar en las cualidades que debe reunir un grupo humano cosmopolita para la construcción de una cosmópolis.

\footnotetext{
8 Traducción por el autor, el texto original dice: "o que está em debate é um fenômeno cultural que, a longo prazo, também teve repercussão sobre as estruturas econômicas, um novo éthos, que representa a quebra da visão tradicional do trabalho e da atividade económica".

9 El texto de Riesebrodt titulado A ética protestante no contexto contemporáneo y cuya referencia se encuentra en la sección correspondiente de este artículo, es un buen documento para introducirse a esta obra de Weber.
} 
Tabla 1. Características del grupo humano protestante

\begin{tabular}{|c|c|c|c|c|}
\hline$\#$ & Pág. & Capítulo & Contexto & Comentario \\
\hline 2 & 3 & Introducción & $\begin{array}{l}{[\ldots] \text { factor destacado en la }} \\
\text { cultura, solo el Occidente } \\
\text { los ha forjado }[\ldots]\end{array}$ & $\begin{array}{l}\text { La especialización del trabajo da } \\
\text { origen a una clase productora de } \\
\text { riqueza, los especialistas. }\end{array}$ \\
\hline 3 & 3 & Introducción & $\begin{array}{l}{[\ldots] \text { en las más diversas cultu- }} \\
\text { ras. Pero, ningún país en }[\ldots]\end{array}$ & $\begin{array}{l}\text { Estos especialistas eran la piedra } \\
\text { angular del estado occidental. }\end{array}$ \\
\hline 4 & 12 & Introducción & $\begin{array}{l}{[\ldots] \text { historia universal de la }} \\
\text { cultura, vista desde el ángulo } \\
\text { puramente económico }[\ldots]\end{array}$ & $\begin{array}{l}\text { El avance de la técnica dio ori- } \\
\text { gen a una clase burguesa menos } \\
\text { orientada a la lucha de clases. }\end{array}$ \\
\hline 9 & 23 & $\begin{array}{l}\text { I - Confesión } \\
\text { y estructura } \\
\text { social }\end{array}$ & $\begin{array}{l}{[\ldots] \text { distinto nivel de desa- }} \\
\text { rrollo cultural de la misma } \\
\text { manera que }[\ldots]\end{array}$ & $\begin{array}{l}\text { Soporta que estadísticamente las } \\
\text { clases privilegiadas son de índole } \\
\text { protestante. }\end{array}$ \\
\hline 10 & 34 & $\begin{array}{l}\text { I - Confesión } \\
\text { y estructura } \\
\text { social }\end{array}$ & $\begin{array}{l}{[\ldots] \text { la superioridad de la }} \\
\text { cultura francesa y holandesa } \\
\text { en el terreno de la economía } \\
{[\ldots]}\end{array}$ & $\begin{array}{l}\text { Aunque suene etnocentrista, el } \\
\text { autor soporta que los grupos hu- } \\
\text { manos protestantes tienden a esta- } \\
\text { blecer relaciones económicas más } \\
\text { amplias fácilmente, pues en com- } \\
\text { paración con católicos gustan de } \\
\text { un estilo de vida menos humilde. }\end{array}$ \\
\hline
\end{tabular}

Fuente: Elaboración propia

La tabla 1 habla de un grupo humano que se diferencia por el uso avanzado de la técnica, la especialización, y consecuentemente, por el aprovechamiento de estas habilidades para establecer relaciones comerciales. Desde el punto de vista cosmopolita, por analogía, sugiere la necesidad de acentuar las diferencias del grupo humano cosmopolita, comprendiendo su papel en el mundo en el sentido de la acción como la define Arendt (1974): "La acción, única actividad que se da entre los hombres sin la mediación de cosas o materia, corresponde a la condición humana de la pluralidad, al hecho de que los hombres, no el Hombre, vivan en la Tierra y habiten en el mundo" (p. 19). De esta forma, una esfera plural de convivencia habría de ser la característica distintiva de quien sea cosmopolita.

Luego, en el análisis, es posible observar qué factores exógenos rodeaban al grupo humano para servir a la idea de ética protestante en Weber. En especial, resulta primordial el papel de la religión, pero más que eso, las racionalizaciones que los inmigrantes puritanos dieron al dogma, con el propósito de colonizar y, a su modo, homogenizar 
la faz de la tierra al ideal que consideraban más avanzado. En este sentido, cabe anotar que algunos cosmopolitismos pretenden cambiar al mundo, otros no. Adicionalmente, hoy en día otros mecanismos diferentes al dogma tienen lugar: quizás la globalización sea una fuerza exógena que fortalezca el proceso de 'cosmopolitización', como lo fue al capitalismo la religión en dicha época. La tabla 2 muestra algunos apartes relacionados.

Tabla 2. Factores exógenos al grupo humano estudiado

\begin{tabular}{|c|c|c|c|c|}
\hline \# & Pág. & Capítulo & Contexto & Comentario \\
\hline 5 & 14 & Introducción & $\begin{array}{l}{[\ldots] \text { su diferencia histórica y }} \\
\text { cultural es, justamente, cuál } \\
\text { o cuáles }[\ldots]\end{array}$ & $\begin{array}{l}\text { Las racionalizaciones de la con- } \\
\text { templación mística son factores } \\
\text { de desarrollo. Estas son vistas } \\
\text { desde la lógica occidental. }\end{array}$ \\
\hline 12 & 37 & $\begin{array}{l}\text { II - El espíritu } \\
\text { del capitalismo }\end{array}$ & $\begin{array}{l}{[\ldots] \text { en la realidad histórica, }} \\
\text { que nosotros enlazamos en } \\
\text { un todo, basándonos en su } \\
\text { significado cultural. }\end{array}$ & $\begin{array}{l}\text { El espíritu del capitalismo es un } \\
\text { producto cultural que trasciende } \\
\text { los límites históricos. }\end{array}$ \\
\hline 15 & 111 & $\begin{array}{l}\text { III - Concep- } \\
\text { ción luterana } \\
\text { de la profesión }\end{array}$ & $\begin{array}{l}{[\ldots] \text { un anhelo humanitario }} \\
\text { de reforma social o de aspi- } \\
\text { raciones culturales. }\end{array}$ & $\begin{array}{l}\text { Las aspiraciones de los padres de } \\
\text { la reforma protestante eran neta- } \\
\text { mente religiosas y sin ánimo de } \\
\text { intervenir la cultura. }\end{array}$ \\
\hline 16 & 122 & $\begin{array}{l}\text { I - Los fun- } \\
\text { damentos } \\
\text { religiosos del } \\
\text { ascetismo laico }\end{array}$ & $\begin{array}{l}{[\ldots] \text { tanto a la religión como }} \\
\text { a la cultura de los pueblos } \\
\text { civilizados más avanzados } \\
{[\ldots]}\end{array}$ & $\begin{array}{l}\text { El dogma de la predestinación } \\
\text { y específicamente el calvinismo } \\
\text { dio origen a los pueblos capita- } \\
\text { listas más civilizados. }\end{array}$ \\
\hline 17 & 124 & $\begin{array}{l}\text { I - Los fun- } \\
\text { damentos } \\
\text { religiosos del } \\
\text { ascetismo laico }\end{array}$ & $\begin{array}{l}{[\ldots] \text { consecuencias históri- }} \\
\text { cas así como a las culturales } \\
\text { del dogma, siendo }[\ldots]\end{array}$ & $\begin{array}{l}\text { Los dogmas religiosos tienen } \\
\text { consecuencias culturales e his- } \\
\text { tóricas. }\end{array}$ \\
\hline 19 & 125 & $\begin{array}{l}\text { I - Los fun- } \\
\text { damentos } \\
\text { religiosos del } \\
\text { ascetismo laico }\end{array}$ & $\begin{array}{l}{[\ldots] \text { grandes contiendas por }} \\
\text { la cultura giraban en torno } \\
\text { del dogma, hasta }[\ldots]\end{array}$ & $\begin{array}{l}\text { El mecanismo de sujeción o } \\
\text { identificación social tradicional } \\
\text { de la época era la religión. }\end{array}$ \\
\hline 20 & 134 & $\begin{array}{l}\text { I - Los fun- } \\
\text { damentos } \\
\text { religiosos del } \\
\text { ascetismo laico }\end{array}$ & $\begin{array}{l}{[\ldots] \text { aflicción y sentimen- }} \\
\text { tales de la cultura y de la } \\
\text { religión en su carácter de } \\
\text { subjetivo }[\ldots]\end{array}$ & $\begin{array}{l}\text { A diferencia de otras religiones, } \\
\text { cada individuo en el protestantis- } \\
\text { mo lograba por sí solo la reden- } \\
\text { ción, sin siquiera la ayuda de Dios. }\end{array}$ \\
\hline 24 & 254 & $\begin{array}{l}\text { II - La relación } \\
\text { entre el ascetis- } \\
\text { mo y el espíritu } \\
\text { capitalista }\end{array}$ & $\begin{array}{l}\text { Bástenos recordar que el es- } \\
\text { parcimiento permitido en los } \\
\text { bienes culturales, se entiende } \\
\text { que únicamente los que bene- } \\
\text { fician el deleite artístico }[. . .]\end{array}$ & $\begin{array}{l}\text { Ningún puritano invierte en } \\
\text { aquello que no esté dirigido a la } \\
\text { honra de Dios. }\end{array}$ \\
\hline
\end{tabular}

Fuente: Elaboración propia 
El análisis realizado también exterioriza las características del espíritu del capitalismo descritas en la obra, que más bien resulta una coincidencia de las particularidades de un grupo humano y unos factores exógenos que los impulsa a trascender su acción, como condición humana en un momento específico del tiempo. Entre estas características se destacan: la libertad, el ascetismo — que más bien parece un individualismo-, el racionalismo, la homogeneidad o convergencia y el uso de medios culturales para trascender o alcanzar objetivos. Desde este punto de vista, se presenta a continuación la tabla 3, que sustenta esta afirmación.

Tabla 3. Características del espíritu del capitalismo

\begin{tabular}{|c|c|c|c|c|}
\hline$\#$ & Pág. & Capítulo & Contexto & Comentario \\
\hline 11 & 37 & $\begin{array}{l}\text { I - Confesión } \\
\text { y estructura } \\
\text { social }\end{array}$ & $\begin{array}{l}{[\ldots] \text { nexo entre ciertas manifesta- }} \\
\text { ciones del protestantismo y de la } \\
\text { cultura capitalista moderna, no } \\
\text { será en el "amor al mundo" }[\ldots]\end{array}$ & $\begin{array}{l}\text { Weber identifica en la piedad, } \\
\text { el comercio y la libertad unos } \\
\text { posibles elementos que dan } \\
\text { vida al capitalismo. }\end{array}$ \\
\hline 12 & 37 & $\begin{array}{l}\text { II - El espíritu } \\
\text { del capitalis- } \\
\text { mo }\end{array}$ & $\begin{array}{l}{[\ldots] \text { en la realidad histórica, que }} \\
\text { nosotros enlazamos en un todo, } \\
\text { basándonos en su significado } \\
\text { cultural. }\end{array}$ & $\begin{array}{l}\text { El espíritu del capitalismo } \\
\text { es un producto cultural que } \\
\text { trasciende los límites histó- } \\
\text { ricos. }\end{array}$ \\
\hline 14 & 111 & $\begin{array}{l}\text { III - Concep- } \\
\text { ción luterana } \\
\text { de la profesión }\end{array}$ & $\begin{array}{l}{[\ldots] \text { fundador de una sociedad de }} \\
\text { cultura ética; tampoco puede de- } \\
\text { cirse que alguno representase }[. . .]\end{array}$ & $\begin{array}{l}\text { El ethos protestante era con- } \\
\text { vergente y compartido entre } \\
\text { sus principales postores }\end{array}$ \\
\hline 18 & 125 & $\begin{array}{l}\text { I - Los fun- } \\
\text { damentos } \\
\text { religiosos del } \\
\text { ascetismo } \\
\text { laico }\end{array}$ & $\begin{array}{l}{[\ldots] \text { topó con el dogma, y su lu- }} \\
\text { cha por la cultura fue un fracaso; } \\
\text { en el seno de la Iglesia anglicana } \\
{[\ldots]}\end{array}$ & $\begin{array}{l}\text { El autor ejemplifica su pos- } \\
\text { tulado anterior con la histo- } \\
\text { ria de un personaje con alto } \\
\text { nivel formativo, el holandés } \\
\text { Johan van Oldenbarnevelt. }\end{array}$ \\
\hline 21 & 253 & $\begin{array}{l}\text { II - La rela- } \\
\text { ción entre el } \\
\text { ascetismo y el } \\
\text { espíritu capi- } \\
\text { talista }\end{array}$ & $\begin{array}{l}\text { Por consiguiente, también la pos- } \\
\text { tura ante los bienes de la cultura, } \\
\text { carentes de valor directo en cuan- } \\
\text { to a la religión, refleja síntomas de } \\
\text { desconfianza, si no de declarada } \\
\text { incompatibilidad. }\end{array}$ & $\begin{array}{l}\text { El ascetismo protestante lu- } \\
\text { chó contra las diversiones de } \\
\text { los regímenes monárquicos } \\
\text { entre ellas algunas manifesta- } \\
\text { ciones artísticas. }\end{array}$ \\
\hline 22 & 253 & $\begin{array}{l}\text { II - La rela- } \\
\text { ción entre el } \\
\text { ascetismo y el } \\
\text { espíritu capi- } \\
\text { talista }\end{array}$ & $\begin{array}{l}\text { No debe interpretarse por ello } \\
\text { que el idealismo de vida del puri- } \\
\text { tano implicara, exactamente, un } \\
\text { áspero prejuicio o una seña lado } \\
\text { desdén hacia la cultura; sin em- } \\
\text { bargo, la realidad es otra, comple- } \\
\text { tamente opuesta, a lo menos por } \\
\text { lo que se refiere a la ciencia [...] }\end{array}$ & $\begin{array}{l}\text { El autor aclara y profundiza } \\
\text { la idea anterior. }\end{array}$ \\
\hline
\end{tabular}




\begin{tabular}{|c|c|c|c|c|}
\hline \# & Pág. & \multicolumn{1}{|c|}{ Capítulo } & \multicolumn{1}{c|}{ Contexto } & \multicolumn{1}{c|}{ Comentario } \\
\hline 23 & 254 & $\begin{array}{l}\text { II - La relación } \\
\text { entre el ascetis- } \\
\text { mo y el espíritu } \\
\text { capitalista }\end{array}$ & $\begin{array}{l}{[\ldots] \text { valerse de esa clase de cul- }} \\
\text { tura en la controversia teológica. } \\
\text { Tal vez no ha existido }[\ldots]\end{array}$ & $\begin{array}{l}\text { Los puritanos también uti- } \\
\text { lizaban algunos medios } \\
\text { culturales para alcanzar sus } \\
\text { objetivos. }\end{array}$ \\
\hline 25 & 281 & $\begin{array}{l}\text { II - La rela- } \\
\text { ción entre el } \\
\text { ascetismo y el } \\
\text { espíritu capi- } \\
\text { talista }\end{array}$ & $\begin{array}{l}\text { y aun de los ascendientes de cul- } \\
\text { tura, así como, con posterioridad, } \\
\text { su relación también con el desen- } \\
\text { volvimiento }[\ldots]\end{array}$ & $\begin{array}{l}\text { El racionalismo ascético y el } \\
\text { racionalismo humanista están } \\
\text { vinculados por la cultura y } \\
\text { los desarrollos científicos. }\end{array}$ \\
\hline
\end{tabular}

Fuente: Elaboración propia

Por supuesto, en la tabla 4 Weber reconoce que su obra tiene limitaciones y las declara explícitamente advirtiendo que no hace un trabajo de religión comparada ni un estudio cultural. De igual forma, el cosmopolitismo debe acatar con humildad sus debilidades para fundar un espíritu cosmopolita.

Tabla 4. Limitaciones del papel de la cultura en la obra

\begin{tabular}{|c|c|c|c|c|}
\hline \# & Pág. & Capítulo & \multicolumn{1}{|c|}{ Contexto } & \multicolumn{1}{c|}{ Comentario } \\
\hline 6 & 16 & Introducción & $\begin{array}{l}{[\ldots] \text { que en cada cultura se ma- }} \\
\text { nifestó en pugna }[\ldots]\end{array}$ & $\begin{array}{l}\text { Alrededor de este término el } \\
\text { autor aclara el alcance y las li- } \\
\text { mitaciones de su obra }\end{array}$ \\
\hline 7 & 18 & Introducción & $\begin{array}{l}{[\ldots] \text { existir entre las distintas }} \\
\text { culturas examinadas comparati- } \\
\text { vamente. No queremos }[\ldots]\end{array}$ & $\begin{array}{l}\text { El autor aclara que no es un } \\
\text { trabajo de religión comparada }\end{array}$ \\
\hline 8 & 18 & Introducción & $\begin{array}{l}{[\ldots] \text { nación encarnaban la res- }} \\
\text { pectiva cultura. Y el caso es, }[\ldots]\end{array}$ & $\begin{array}{l}\text { El autor aclara que no es un } \\
\text { trabajo netamente de estudio } \\
\text { cultural }\end{array}$ \\
\hline
\end{tabular}

Fuente: Elaboración propia

El cosmopolitismo cimentado en la cultura encuentra inspiración en la obra de Weber como base para la reflexión acerca del comportamiento del hombre en sociedad. La cultura es el origen de la pregunta guía de La ética protestante y el espíritu del capitalismo, es la razón por la cual nació una clase social de especialistas que se convirtió en piedra angular del estado. Además, aunque de manera difusa, es la cultura quien participa en la materialización de valores en costumbres, o como Weber diría, racionalizaciones de la contemplación mística. Cada cultura, podrá entonces racionalizar aquello en lo cual enfatice 
para convertirlo en un mecanismo de dominación del individuo, o de masificación de la sociedad.

La estructura argumentativa de cada capítulo del texto, en medidas se frecuencia, se soporta en la cultura como se ve en la tabla 5 .

Tabla 5: Frecuencia de uso de la palabra cultura por capítulo

\begin{tabular}{|l|c|}
\hline \multicolumn{1}{|c|}{ Sección } & Menciones \\
\hline Introducción & 8 \\
\hline I - Confesión y estructura social & 3 \\
\hline II - El espíritu del capitalismo & 2 \\
\hline III - Concepción luterana de la profesión & 2 \\
\hline I - Los fundamentos religiosos del ascetismo laico & 5 \\
\hline II - La relación entre el ascetismo y el espíritu capitalista & 7 \\
\hline
\end{tabular}

Fuente: Elaboración propia

De la tabla anterior, es interesante observar que los capítulos de inicio y de cierre del texto son los que más mencionan la palabra 'cultura'. No es posible suponer que sean determinantes en el esquema argumentativo sin un análisis más profundo, pero no deja de llamar la atención. Se observa que los puntos neurálgicos para soportar la existencia de un espíritu capitalista y su alojamiento en un grupo social están ubicados precisamente en la introducción y las conclusiones. Específicamente, la última sección reafirma la necesidad de estudiar los grupos humanos y las transformaciones que genera en ellos la cultura como se ve en la tabla 6.

Tabla 6. El estudio de la cultura para entender los grupos humanos

\begin{tabular}{|c|c|c|c|c|}
\hline$\#$ & Pág. & Capítulo & Contexto & Comentario \\
\hline 26 & 282 & $\begin{array}{l}\text { II - La relación } \\
\text { entre el ascetis- } \\
\text { mo y el espíritu } \\
\text { capitalista }\end{array}$ & $\begin{array}{l}{[\ldots] \text { básicos por el conjunto }} \\
\text { de las condiciones en que se } \\
\text { encontraba la cultura y la so- } \\
\text { ciedad, en especial las econó- } \\
\text { micas }[. . .]\end{array}$ & $\begin{array}{l}\text { Weber indica que es necesario } \\
\text { un estudio de la cultura donde } \\
\text { nació su espíritu capitalista. }\end{array}$ \\
\hline 27 & 282 & $\begin{array}{l}\text { II - La relación } \\
\text { entre el ascetis- } \\
\text { mo y el espíritu } \\
\text { capitalista }\end{array}$ & $\begin{array}{l}{[\ldots] \text { suplantar una percepción }} \\
\text { unilateralmente "materialista" } \\
\text { de la cultura y de la historia } \\
\text { por otra en contraposición al } \\
\text { espiritualismo de }[. . .]\end{array}$ & $\begin{array}{l}\text { La cultura es un elemento insu- } \\
\text { perable en el entendimiento de } \\
\text { un espiritualismo manifiesto en } \\
\text { un grupo social, aunque genere } \\
\text { problemas de interpretación. }\end{array}$ \\
\hline
\end{tabular}

Fuente: Elaboración propia 
No obstante, como el mismo Weber (2003) reconoce, su trabajo no es netamente de análisis cultural. Esto no es inconveniente, porque de la misma forma está tejido el cosmopolitismo: no es un ejercicio puramente cultural, pero encuentra sus raíces en estos fenómenos, razón por la cual, la cultura -y los gustos derivados o racionalizaciones como diría Weber- son calificados como obstáculos con motivo de los problemas de interpretación asociados.

A pesar de que el diagnóstico weberiano resulte en una posible pérdida del sentido y la libertad del individuo (Gronow, 1988), lo cual podría ir en contra de las bases de un cosmopolitismo político específicamente, demuestra que las racionalizaciones no tienen validez universal, sino que yacen en una cultura racional aristocrática, no esencial, pero que sí propende por la selección coherente de estas racionalizaciones (Weber, 2012). Esa es la posible clave de una cosmópolis.

Lo interesante de observar con ojos cosmopolitas o de indagar en la obra weberiana por inspiración para el cosmopolitismo es trascender en el hecho de que ningún problema humano será resuelto hoy de manera completa por alguna religión, filosofía, tradición, ideología o cultura (Panikkar, 1999). En otras palabras, aunque Weber afirma descifrar las claves del espíritu del capitalismo en un ethos alojado en un grupo humano, hoy su apreciación podría estar en tela de juicio. Para denominar universal una explicación como esta, tal y como inicia La ética protestante y el espíritu del capitalismo, ${ }^{10}$ la mirada de los problemas humanos con enfoque weberiano debe desprenderse del esencialismo cultural de la misma manera en que el cosmopolitismo se propone. Así, el camino sociológico prospectivo puede ser más claro al evitar alinear religiones, filosofías, tradiciones, ideologías o culturas para la búsqueda de explicaciones, desde luego, bajo alguna estrategia de transformación de la sociedad. El cosmopolitismo acude entonces a la educación para sus propósitos.

10 " [...] solo aquí, se hayan dado ciertas manifestaciones culturales, mismas que - al menos tal y como solemos representárnoslas- se encuentran en una dirección evolutiva de alcance y validez universales" (Weber, 2003, p. 53). 


\section{El espíritu del cosmopolitismo: educación más allá del esencialismo cultural en un estado plural}

Si el cosmopolitismo desea convertirse en una propuesta viable, debe buscar inspiración en diferentes corrientes para aprovechar los factores exógenos que lo benefician y, especialmente, en la globalización. ${ }^{11}$ "En La ética protestante y el espíritu del capitalismo, Weber sigue en efecto un enfoque culturalista, ya que se trata de evidenciar un ethos, aunque no esté enmarcado por un sistema económico" (Riesebrodt, 2012, p. 168). ${ }^{12}$ De esta manera, la concepción weberiana del espíritu del capitalismo y de la cultura, basada en las estructuras de valores, es una importante inspiración para diseñar mecanismos de transformación social, apelando también a la insistencia de Weber en que la cultura puede cambiar (Ringer, 2009; Zeuner, 2003).

El espíritu del cosmopolitismo debe nacer en la posibilidad abierta de diferencias. Es un problema de vecindad global en la cual, cada individuo, cada grupo humano, cada sociedad y cada cultura, se enfrentan a las consecuencias éticas de su estilo de vida. Es un problema de construir menos instituciones estatales y más sistemas de convivencia global (Reder, 2012). Las propuestas más discutidas están orientadas alrededor de la educación como mecanismo de formación de ciudadanos del mundo, verdaderos cosmopolitas. Desde otro punto de vista, pero soportando la idea anterior, el cosmopolitismo es también "un conjunto de proyectos dirigidos a la convivencia planetaria” (Mignolo, 2000, p. 721), ${ }^{13}$ lo cual implica la construcción de un metalenguaje integrador.

Ante un panorama de globalización y la necesidad del surgimiento de un nuevo nomos de la tierra (Schmitt, 2002), esta vez centrado

\footnotetext{
11 Reder (2012) define globalización como "la intensificación y aceleración de las relaciones transfronterizas en los ámbitos más dispares, como la política, la economía o la cultura" (p. 10).

12 Traducción por el autor, el texto original dice: "Na "Ética protestante", Weber segue de fato um enfoque culturalista, já que trata de evidenciar um éthos, enquanto não moldado por um sistema económico".

13 Traducción por el autor, el texto original dice: "a set of projects toward planetary conviviality".
} 
en sistemas en vez de territorialidades politizadas, surgen múltiples propuestas para darle sentido al espíritu del cosmopolitismo. Entre otros, aparecen discursos pluralistas, liberalistas, universalistas, realistas, comunitaristas y otros centrados en justicia global, igualitarismo, derechos humanos y supranacionalidad. Pero su verdadero impacto debe estar en el relacionamiento entre diferentes culturas que, más que un diálogo, exige un polílogo. Esto implica que existan "diversidad de formas sociales y perspectivas. La cultura se convierte aquí en un modelo analítico con el que se puede describir, y también explicar, esta diversidad" (Reder, 2012, p. 50).

Precisando la idea anterior, el panorama mencionado implica que el problema abordable es la política y el problema relevante es la cultura (Tröhler, 2009). Es necesaria una hermenéutica que cambie la interpretación humana del cruce cultural y de las civilizaciones para redefinir el cuerpo teórico de la política (Gebhardt, 2008). Es un llamado a evitar explicaciones desde la religión, filosofía, tradiciones, ideologías o culturas que resulta paradójico para el científico. Pero tiene sentido en cuanto elimina los peligros asociados a la filosofía de la religión (Gall, 1998) y al esencialismo cultural (Olson, 2011), por mencionar dos específicamente.

Strand (2010) y Papastephanou (2005) afirman que la educación es una salida racional a las barreras insalvables de la cultura y los gustos. No son ellas las únicas autoras en esta línea, Nussbaum (2002) afirma que el cosmopolitismo reside en la educación para la ciudadanía global, la imaginación narrativa de carácter empático y el conocimiento de las artes y tradiciones culturales propias.

La propuesta de Strand (2010) cuenta con tres secciones a ser incluidas en la educación: 1. El cosmopolitismo como metáfora de vida, 2. El cosmopolitismo como un universo simbólico y 3 . Las paradojas del cosmopolitismo. La primera sección se desarrolla entre la revisión de diversos autores, quienes han elaborado sus propuestas alrededor de conceptos como globalización, cosmópolis, ciudadanía global, justicia global y otros ideales que conforman el imaginario del movimiento. Dada la variedad, estos imaginarios se ubican en un complejo 
contexto de interdependencia social, en el cual se hace necesaria una visión cosmopolita (Beck, 2006).

La segunda parte de la propuesta mencionada enseña cómo la construcción del término cosmopolita se funda en una metáfora etimológica al yuxtaponer la creación de dios con la creación de los hombres - cosmos y polis-, el universalismo y el particularismo conviviendo de forma armoniosa. Seguidamente, la tercera parte afirma que la imagen usada para dar vida al cosmopolitismo es la causa de las dificultades para su asimilación en los procesos sociales. Las utopías descritas son una metáfora, que rompen con las estructuras actuales de conformación de la sociedad. Realmente, ante un panorama global, somos más extraños que conocidos quienes pisamos la faz de la tierra:

Consecuentemente, el trabajo principal del cosmopolitismo no es contribuir a la expansión del conocimiento, sino a los medios por los cuales el nuevo cosmopolitismo instituye nuevos modos de aprender, y así, nuevas formas de sentir, ver y conocer un mundo globalizado de cambios (Strand, 2010, p. 240-241). ${ }^{14}$

Como se infiere del inciso anterior, la visión de Strand (2010) implica un gran esfuerzo hermenéutico y pedagógico, pero otras propuestas aterrizan en conceptos ideales como la singularidad. Vaughan-Williams (2007) también supone la necesidad de nuevos imaginarios, cuyo punto de partida para el dominio de lo ético-político sea la singularidad. Para el autor, siguiendo la línea de Derrida (2002), la estructura política contemporánea ya no debe ser dada por ciudadanos, sujetos políticos, o ni siquiera humanos, sino por singularidades. Estos entes tienen la capacidad de establecer relaciones ético-políticas con todas las formas de vida, ampliando el espectro social a la interrelación entre la pluralidad y la singularidad, las cuales cobran sentido en la existencia recíproca. De esta manera, la responsabilidad compartida

\footnotetext{
14 Traducción por el autor, el texto original dice: "Consequently, the vital work of cosmopolitanism is not in the ways in which it may contribute to a growth of knowledge; rather, the vital work is in the ways in which the new cosmopolitanism institutes radically new modes of learning, and thus completely new ways of experiencing, seeing and knowing a globalised world of change".
} 
obliga a cambiar las relaciones que se establecen en el mundo hacia un bien superior (Roth, 2012).

Papastephanou (2005) coincide con lo anterior al aseverar que el cambio de las relaciones en el mundo es necesario si se quiere ver una convivencia cosmopolita. Pero afirma que es necesario escapar de las implicaciones de auto indulgencia, complacencia, e idealización del cosmopolita (Papastephanou, 2013). También, requiere reconocer que la educación, la incertidumbre y la humanidad compartida son condiciones humanas del cosmopolitismo (Hayden, 2012), que en el marco de la globalización planetaria deben ser orientadas por criterios éticos.

Giri (2006) asevera que el "cosmopolitismo como conversaciones planetarias nos lleva más allá del cosmopolitismo que conocemos" (p. 1289), ${ }^{15}$ para soportar su idea de que la propuesta universalista por la cual pasó el primer cosmopolitismo no es completamente conveniente y que, más bien, se debe hablar de un multiverso de conversaciones traslapadas que no necesariamente se encuentran en el consenso. De alguna manera, este cosmopolitismo de avanzada contradice los principios de la democracia y de las estructuras actuales de gobierno, configurando una paradoja que se podría llamar cosmopolítica. Entonces, dado que la democracia suele ser listada como una condición para el universalismo (Ricco, 2011), y que su mecanismo de funcionamiento colapsa en el multiverso donde la representación es ciertamente ambigua, el cosmopolitismo a trabajar apunta a una tendencia más allá del fenómeno político. En otras palabras, el cosmopolitismo político debería pasar a un segundo plano en comparación con los otros tipos de cosmopolitismo.

En la búsqueda de una cosmópolis, cada discurso político tiene sus detractores (Toulmin, 1992), pero desde otros puntos de vista - económico, cultural y social- hay consenso sobre el papel de la educación (Papastephanou, 2011; Strydom, 2012). Por ejemplo, al respecto de los derechos humanos en las propuestas de Bohman

15 Traducción por el autor, el texto original dice: "cosmopolitanism as planetary conversations take us beyond the cosmopolitanism we know". 
(2007) y Goodhart (2008), hay quienes afirman que no son soporte suficiente para una democracia global. Según Erman (2011), ambos autores parten de un supuesto cuestionable al entregar las bases de la democracia global a los derechos humanos. Por ende, si ellos fueran "más claros con la distinción entre ideales normativos y métodos y reglas de decisión (por ejemplo normas, instituciones y leyes) para regular las interacciones sociales, [...] sus respectivas teorías serían cada vez más atractivas" (Erman, 2011, p. 480). ${ }^{16}$ Aunque el texto de Weber, impregnado por supuesto de un tinte político, se acerca en cierta forma a un pluralismo o un liberalismo, él nunca hubiera podido imaginar qué implicaciones tendría la globalización en las interacciones sociales un siglo después de su muerte.

Se concuerda con Weber al observar tintes liberales en las corrientes de masificación asociadas al capitalismo. Más cuando él "aspiraba con el liberalismo a defender hasta donde fuera posible la libertad, entendía que el espíritu de consenso y de neutralizar los conflictos del liberalismo era una mala estrategia, pues no hacía frente a los verdaderos obstáculos que a la libertad oponía la sociedad de masas" (Villacañas, 2005, p. 122). En otras palabras, Weber reconoce que el consenso no es natural a la sociedad de masas y por ende no será fácil fundar un gobierno global si se retoman los principales obstáculos de su proyecto social, es decir, las diferencias de cultura y de gustos.

Sabiendo que los seres humanos continúan su apego a la cultura como programación colectiva de la mente de su país de origen, otro punto interesante emerge en esta lectura: ¿existe un cosmopolitismo secular? Dar una respuesta a este interrogante resulta más que complicado, utópico, porque requiere necesariamente como condición que cada religión exprese dentro de la cultura que "se expropia de su singularidad y enturbie su certeza de ser la única 'verdadera' y 'justa”, (Balibar, 2011, p. 22)..$^{17}$

\footnotetext{
16 Traducción por el autor, el texto original dice: "clearer on the distinction between normative ideals and decision methods and rules (for example, norms, institutions and law) for regulating social interactions, $[\ldots]$ their respective theories would become even more attractive".

17 Traducción por el autor, el texto original dice: "expropriate' them of their own singularity and disturb their certainty of being uniquely 'true' and 'just".
} 
Entonces, si el problema radica en los instrumentos de la cultura para la sujeción de los individuos (Bustamante, Arboleda \& Gutiérrez, 2010) y en especial las verdades últimas planteadas por la religión, tiene sentido pensar en otro instrumento que pueda hacer contrapeso. La educación acompañada con la enseñanza apropiada de conceptos referentes a la ciudadanía global debería ser un ideal que promueva la convivencia, "si el mayor problema es cambiar la consciencia de las personas, la educación tiene una carga pesada, porque las personas generalmente se convierten en aquello que se les enseña a ser" (Papastephanou, 2005, p. 548). ${ }^{18}$ Pero el hecho de listar los valores, ideas y conceptos que fundan un cosmopolitismo aplicable por medio de un sistema educativo, es de por sí un gran reto. En adición, los problemas de investigación situados en la era de la globalización se caracterizan por enmarcarse dentro de una intrincada red de conceptos, contextos y situaciones interdependientes.

Con todo el debate pedagógico planteado, no tiene por qué haber una divergencia entre liberalismo, cosmopolitismo y nacionalismo que dé origen a conflictos políticos, siempre que haya bases sentadas. Hechos recientes demuestran que hay un resurgimiento de movimientos nacionalistas y, de distintas maneras, mientras que los objetivos del liberalismo y el nacionalismo se encuentren enfocados hacia una posible justicia global, "nuestros principios de distribución debería aplicarse a todos los individuos del globo, y no estar restringidos o deformados por ninguna barrera nacional" (Kok-Chor, 2002, p. 444). ${ }^{19}$ Entonces, la posibilidad de una convivencia global, y la formación de un espíritu cosmopolita necesitado de respuestas a los retos de la globalización, encuentra inspiración en la obra de Max Weber, si se aborda desde una lectura cosmopolita que tiene como objetivo la intervención de la realidad por vía de la educación.

\footnotetext{
18 Traducción por el autor, el texto original dice: "If the major issue is to change the consciousness of people, then education has a beavy burden, because people often become what they are tanght that they are".

19 Traducción por el autor, el texto original dice: "ourprinciples of distribution onght to apply to all individuals globally, and not be restricted and shaped by national boundaries".
} 


\section{Conclusiones}

Antes de hacer un comentario a manera de conclusiones, conviene revisar las debilidades de este texto para que otras investigaciones lo complementen y, además, lo critiquen. El análisis de una sola edición de La ética protestante y el espiritu del capitalismo es un primer elemento a mejorar: sería necesario analizar diferentes ediciones o en particular la edición en idioma original. En segundo lugar, es necesario aclarar que este artículo no pretende dar cuenta de un conocimiento profundo de la obra de Max Weber, sino, inspirar un debate en el cosmopolitismo después de la aplicación de un método de análisis de contenido que origina ideas basadas en las barreras insalvables de los gustos y la cultura. En tercer lugar, el cosmopolitismo por sí mismo tiene una carga ideológica que lo ubica como un deber ser, un estado ideal de cualquier esfera de la existencia del hombre. Lo anterior es necesario asumirlo con distancia y más bien ver en el cosmopolitismo una propuesta con aciertos y desaciertos. Por último, conviene advertir al lector que la obra de Weber es compleja, posee múltiples interpretaciones y se conecta de diversas formas durante la vida del autor, por tal motivo persiste una inquietud sobre la completitud de este artículo.

De otro lado, Weber no era un cosmopolita y su obra en general no está catalogada dentro del cosmopolitismo. Más bien, su estudio estuvo altamente influenciado por su cultura, y presenta tintes etnocentristas. Pero su trabajo en La ética protestante y el espiritu del capitalismo arroja importantes elementos para inspirar una reflexión cosmopolita: 1. Explica la posibilidad de relacionar un ethos dentro del estudio de un grupo humano, 2. Inspira una posible estructura metodológica para fundar un espíritu cosmopolita y 3 . Enseña que las racionalizaciones tienen un espectro espacio-temporal sobre el cual adquieren sentido. El cosmopolitismo también se ha reformado para absorber nuevos valores que lo soporten como idea, pero requiere fundamentos políticos para el contexto actual, basados en una estructura teórica sistematizada y en métodos para estudiar la sociedad y las posibilidades reales de un gobierno global. Mientras lo anterior no sea solucionado, los programas educativos del cosmopolitismo tendrán carácter provisional. 
Se erige un objetivo en el estudio de los problemas asociados a la estructura estatal-nacional para la conformación de ciudadanía global más allá del pluralismo: preguntarse por la precedencia de los valores que hacen posible la convivencia (Strokes, 2004). Es allí donde la obra de Weber puede inspirar mayormente al cosmopolitismo al presentar una guía para dar forma al espíritu cosmopolita. El siguiente párrafo de Panikkar (1995) resulta ilustrativo para cerrar esta discusión:

Hoy el significado de la palabra [pluralismo] está cambiando de un locus existencial sociológico a uno metafísico que nos ayuda a descubrir sus raíces. El pluralismo hoy un problema existencial humano que genera cuestionamientos sobre cómo vamos a vivir nuestras vidas en medio de tantas opciones. El pluralismo ya no es el antiguo texto de escuela que cuestiona sobre el Individuos y los Demás; se ha convertido en un dilema concreto del día a día ocasionado por el encuentro de visiones del mundo y filosofías mutuamente incompatibles. Hoy se ve el pluralismo como la pregunta práctica sobre la coexistencia humana planetaria. (p. 56). ${ }^{20}$

Dicho lo anterior, las dudas remanentes son: ¿Cuáles son las características y racionalizaciones necesarias para la existencia del espíritu cosmopolita?, ¿persistirán y surgirán nuevos obstáculos para la existencia de una cosmópolis?, ${ }^{21}$ y ¿cómo resolver la dispersión y la falta de estructura del cuerpo teórico del cosmopolitismo sobre la cual debe hallar suelo fértil la construcción de nuevas propuestas?

\footnotetext{
20 Traducción por el autor, el texto original dice: "Today the meaning of the word [pluralism] is shifting from a sociological and metaphysical to an existential locus, which helps us discover its roots. Pluralism is today a human existential problem which raises acute questions about how we are going to live our lives in the midst of so many options. Pluralism is no longer just the old schoolbook question about the One and the Many; it has become a concrete day-to-day dilemma occasioned by the encounter of mutually incompatible worldviews and philosophies. Today we face pluralism as the very practical question of planetary buman coexistence".

21 De acuerdo con Barry \& Valentini (2009) son siete los obstáculos que obstaculizan el cosmopolitismo: las críticas al igualitarismo, la cooperación social, la coerción estatal, la agencia, la responsabilidad nacional, los significados sociales compartidos y el pluralismo internacional.
} 


\section{Referencias}

Aguiló, A. (2010). Hermenéutica diatópica, localismos globalizados y nuevos imperialismos culturales: orientaciones para el diálogo intercultural. Cuadernos Interculturales, 8(14), 145-163.

Appiah, K. (2007). Cosmopolitanism: Ethics in a world of strangers. New York: W. W. Norton.

Arendt, H. (1974). La condición bumana. Barcelona: Editorial Seix Barral. Baldwin, J., Faulkner, S., Hecht, M., \& Lindsey, S. L. (Edits.) (2006). Redefining Culture. Mahwah: Laurence Erlbaum Associates.

Balibar, É. (2011). Cosmopolitanism and Secularism: Controversial Legacies and Prospective Interrogations. Grey Room, 44(1), 7-53.

Ballesteros, M. (1962). La cultura y las culturas. Anthopos, 57(3/6), 345-356.

Barry, C., \& Valentini, L. (2009). Egalitarian challenges to global egalitarianism: A critique. Review of International Studies, 35(3), 485-512.

Beck, U. (2002). The cosmopolitan society and its enemies. Theory, Culture and Society, 19(1), 17-44.

Beck, U. (2004). Cosmopolitical realism: On the distinction between cosmopolitanism in philosophy and the social sciences. Global Networks, 4, 131-156.

Beck, U. (2006). Cosmopolitan vision. Cambridge: Polity Press.

Beck, U., \& Sznaider, N. (2006). A literature on cosmopolitanism: an overview. The British Journal of Sociology, 57(1), 153-164.

Bernard, R., \& Ryan, G. (2010). Analyzing Qualitative Data: Systematic Approaches. California: SAGE Publications.

Bohman, J. (2007). Democracy across Borders: From De'mos to De moi. Cambridge: MIT Press.

Bustamante, L., Arboleda, A., \& Gutiérrez, J. (enero-junio, 2010). Cultura, política industrial y competitividad internacional de PyMEs en Colombia. Revista Ad-Minister, 16, 83-98.

Colic-Peisker, V. (2010). Free floating in the cosmopolis? Exploring the identity-belonging of transnational knowledge workers. Global Networks, 10(4), 467-488.

Dallmayr, F. (2005). Empire or cosmopolis? Civilization at the crossroads. Globalizations, 2(1), 14-30. 
Delanty, G. (2006). The cosmopolitan imagination: Critical cosmopolitanism and social theory. British Journal of Sociology, 57(1), 25-47.

Delanty, G. (2009). The cosmopolitan imagination: The renewal of critical social theory. Cambridge: Cambridge University Press.

Delanty, G. (2012). A cosmopolitan approach to the explanation of social change: Social mechanisms, processes, modernity. Sociological Review, $60(2), 333-354$.

Delanty, G., \& Inglis, D. (2011). Introduction: An overview of the field of cosmopolitan studies. En G. Delanty, \& D. Inglis (Edits.), Cosmopolitanism: Critical concepts in the social sciences (pp. 1-27). London: Routledge.

Derrida, J. (2002). On Cosmopolitanism and Forgiveness. Padstow: Routledge.

Desmond, W. (2008). Cynics. California: University of California Press.

Egan, E. (2004). Peace Be with You: Justified Warfare or the Way of Nonviolence. Eugene: Wipf and Stock Publishers.

Erman, E. (2011). Human rights do not make global democracy. Contemporary Political Theory, 10(4), 463-481.

Feldman, N. (2007). Cosmopolitan Law? Yale Law Journal, 116(5), 1022-1070.

Gall, R. (1998). Danger: Philosophy of religion. Philosopby Today, 42(4), 393-401.

Gebhardt, J. (2008). Political thought in an intercivilizational perspective: A critical reflection. The Review of Politics, 70(1), 5-22.

Geertz, C. (1995). La interpretación de las culturas. Barcelona: Gedisa.

Giri, A. (2006). Cosmopolitanism and Beyond: Towards a Multiverse of Transformations. Development \& Change, 37(6), 1277-1292.

Goldwaser, N. (2009). La vigencia del pensamiento de Max Weber a cien años de "La ética protestante y el espíritu del capitalismo". Diánoia, 54(62), 149-154.

Goodhart, M. (2008). Human rights and global democracy. Ethics \& International Affairs, 22(4), 395-420.

Gronow, J. (1988). The Element of Irrationality: Max Weber's Diagnosis of Modern Culture. Acta Sociologica, 31(4), 319-331.

Hannerz, U. (1990). Cosmopolitans and locals in world culture. Theory, Culture and Society, 7, 237-251.

Hansen, D. (2010). Chasing Butterflies Without a Net: Interpreting Cosmopolitanism. Studies in Philosopby \& Education, 29(2), 151-166. 
Hayden, M. (2012). Arendt and cosmopolitanism: The human conditions of cosmopolitan teacher education. Ethics and Global Politics, 5(4), 239-258.

Held, D. (1995). Democracy and the global order: From the nationstate to cosmopolitan governance. Cambridge: Polity Press.

Held, D. (2002). Cosmopolitanism: Ideas, realities and deficits. En D. Held, \& A. McGrew (Edits.), Governing globalization (pp. 305-320). Cambridge: Polity Press.

Held, D. (2010). Cosmopolitanism: Ideals and realities. Cambridge: Polity Press. Hennis, W. (1983). El problema central de Max Weber. Revista de Estudios Politicos 33, 49-99.

Jacobs, A. (2010). Max Weber was Right about the Preconditions, Just Wrong about Japan: The Japanese Ethic and its Spirit of Capitalism. Open Area Studies Journal, 3, 12-29.

Janssens, M., \& Steyaert, C. (2012). Towards an ethical research agenda for international HRM: The possibilities of a plural cosmopolitan framework. Journal of Business Ethics, 111(1), 61-72.

Kant, I. (1784). Idea for a universal history with a cosmopolitan purpose. Recuperado de http://yalepress.yale.edu/yupbooks/excerpts/kant_perpetual.pdf

Kleingeld, P., \& Brown, E. (2002). Cosmopolitanism. Recuperado de http:// plato.stanford.edu/archives/fall2002/entries/cosmopolitanism/

Kok-Chor, T. (2002). Liberal Nationalism and Cosmopolitan Justice. Ethical Theory and Moral Practice, 5(4), 431-461.

Leung, K., Bhagat, R., Buchan, N., Erez, M., \& Gibson, C. (2005). Culture and international business: Recent advances and their implications for the future. Journal of International Business Studies, 36(4), 357-378.

Martindale, D. (1971). Max Weber on the Sociology and Theory of Civilization. International Journal of Contemporary Sociology, 8, 1-12.

Martínez, I. (1997). Los dos conceptos de cultura: Entre la oposición y la confusión. Revista Española de Investigaciones Sociológicas, 79, 173-196.

Matin-Asgari, A. (2004). Islamic Studies and the Spirit of Max Weber: A Critique of Cultural Essentialism. Critique: Critical Middle Eastern Studies, 13(3), 293-312.

Mau, S., Mewes, J., \& Zimmermann, A. (2008). Cosmopolitan attitudes through transnational social practices? Global Networks, 8(1), 1-24.

McCarthy, R. (2011). Toward a Cosmopolitical Democracy: Process over Ends. Journal of International \& Global Studies, 2(2), 21-43. 
Mignolo, W. (2000). The Many Faces of Cosmo-polis: Border Thinking and Critical Cosmopolitanism. Public Culture, 12(3), 721-749.

Nussbaum, M. (1994). Patriotism and cosmopolitanism. Boston Review, 19(5), 3-34.

Nussbaum, M. (1997). Kant and Stoic Cosmopolitanism. Journal of Political Philosophy, 5(1), 1-25.

Nussbaum, M. (2002). Education for citizenship in an era of global connection. Studies in Philosophy and Education, 21, 289-303.

Olson, L. (2011). The Essentiality of 'Culture' in the Study of Religion and Politics. Journal for the Scientific Study of Religion, 50(4), 639-653.

Panikkar, R. (1995). Invisible Harmony Essays on Contemplation \& Responsibility. Minneapolis: Augsburg Fortress Publishing.

Panikkar, R. (1999). El espíritu de la política: homo politicus. Barcelona: Península. Papastephanou, M. (2005). Globalisation, Globalism and Cosmopolitanism as an Educational Ideal. Educational Philosophy \& Theory, 37(4), 533-551. Papastephanou, M. (2011). The 'Cosmopolitan' Self does her Homework. Journal of Philosophy of Education, 45(4), 597-612.

Papastephanou, M. (2013). Being and Becoming Cosmopolitan: Higher Education and the Cosmopolitan Self. International Journal of Higher Education, 2(2), 184-194.

Pieterse, J. (2006). Emancipatory Cosmopolitanism: Towards an Agenda. Development \& Change, 37(6), 1247-1257.

Reder, M. (2012). Globalización y Filosofía. Barcelona: Herder.

Reno, R. (2008). Cosmopolitanism with Real Roots. Modern Age, 50(2), 132-135.

Ricco, M. (2011). Democracy as a "Universal Value" and an Intercultural Ethics. Cultura: International. Journal of Philosophy of Culture \& Axio$\log y, 8(2), 73-84$.

Riesebrodt, M. (2012). A ética protestante no contexto contemporâneo. Tempo Social, 24(1), 159-182.

Ringer, F. (2009). Max Weber's Methodology: The Unification of the Cultural and Social Sciences. Boston: Harvard University Press.

Rodríguez, J. (Ed.). (2005). En el centenario de La ética protestante y el espiritu del capitalismo. Madrid: Centro de Investigaciones Sociológicas.

Roth, K. (2012). A cosmopolitan design of teacher education and a progressive orientation towards the highest good. Ethics and Global Politics, 5(4), 259-279. 
Sanderson, S., Abrutyn, S., \& Proctor, K. (2011). Testing the Protestant Ethic Thesis with Quantitative Historical Data: A Research Note. Social Forces, 89(3), 905-911.

Scheffler, S. (1999). Conceptions of Cosmopolitanism. Utilitas, 11, 255-276. Schmitt, C. (2002). ElNomos de la Tierra en el Derecho de Gentes del «Ius Publicum Europaeum». Granada: COMARES S.L.

Schroeder, R. (1992). Max Weber and the Sociology of Culture. London: Sage Publications.

Shelton, D. (2013). The Oxford Handbook of International Human Rights Law. Oxford: Oxford University Press.

Strand, T. (2010). The making of a new cosmopolitanism. Studies in Philosophy and Education, 29(2), 229-242.

Strokes, G. (2004). Global citizenship. Ethos: ideas for the classroom discussions and reviews, 12(1), 19-23.

Strydom, P. (2012). Toward a global cosmopolis? On the formation of a cosmopolitan cultural model. Irish Journal of Sociology, 20(2), 1-28.

Toulmin, S. (1992). Cosmopolis: The Hidden Agenda of Modernity. Chicago: University of Chicago Press.

Tröhler, D. (2009). Globalizing Globalization: The Neo-Institutional Concept of a World Culture. Yearbook of the National Society for the Study of Education, 108(2), 29-48.

Vaughan-Williams, N. (2007). Beyond a cosmopolitan ideal: The politics of Singularity. International Politics, 44(1), 107-130.

Villacañas, J. (2005). Max Weber entre liberalismo y republicanismo. Isegoría. Revista de Filosofía Moral y Politica, 33, 127-141.

Villacañas, J. (2009). Max Weber sobre Judaísmo. En J. Fernández (Ed.), Judaísmo finito, judaísmo infinito: debates sobre el pensamiento judio contemporáneo (pp. 53-93). Murcia: Tres Fronteras.

Weber, M. (1949). The Methodology of the Social Sciences. Glencoe: The Free Press.

Weber, M. (1968). The religion of China: Confucianism and Taoism. New York: Free Press.

Weber, M. (1991). La ética protestante y el espiritu del capitalismo. México D.F.: Premià.

Weber, M. (2003). La ética protestante y el espiritu del capitalismo. México: Fondo de Cultura Económica. 
Cosmopolitismo y LAS baRReras insalvables de LA cultura y Los gustos / 45

Weber, M. (2012). Sociología de la Religión. Madrid: Ediciones Akal.

Zeuner, L. (2003). Cultural Sociology from Concern to Distance. Copenhagen:

Copenhagen Business School Press. 
